\title{
Tsafon
}

Revue d'études juives du Nord

$74 \mid 2017$

La Déclaration Balfour, vers l'État d'Israël ?

\section{Journée d'études : Moïse dans tous ses états}

\section{(2) OpenEdition}

1 Journals

Édition électronique

URL : https://journals.openedition.org/tsafon/422

DOI : $10.4000 /$ tsafon.422

ISSN : 2609-6420

Éditeur

Association Jean-Marie Delmaire

\section{Édition imprimée}

Date de publication : 1 décembre 2017

Pagination : 160-161

ISSN : 1149-6630

\section{Référence électronique}

"Journée d'études: Moïse dans tous ses états », Tsafon [En ligne], 74 | 2017, mis en ligne le 31 mai

2018, consulté le 25 juin 2021. URL : http://journals.openedition.org/tsafon/422 ; DOI : https://doi.org/ 10.4000/tsafon.422

Ce document a été généré automatiquement le 25 juin 2021.

Tsafon. Revues d'études juives du Nord 


\section{Journée d'études : Moïse dans tous ses états}

\section{RÉFÉRENCE}

Journée d'études : Moïse dans tous ses états, 17 novembre 2017, Lille.

1 Cette journée d'étude a été organisée conjointement par la Faculté de Théologie de Lille et par l'Acfeb (Association Catholique française pour l'étude de la Bible), dont plusieurs intervenants sont membres et qui a pour objectif de promouvoir l'étude de la Bible dans le contexte académique et pastoral. Elle rassemble des personnes engagées dans le travail biblique, aussi bien dans le monde universitaire que dans le monde de la formation, la paroisse, ou à titre personnel.

2 Cette journée a également été placée également sous le patronage de l'IEFR (Institut d'Étude des Faits Religieux, université d'Artois), et du GRETREPO (groupe de recherche sur les traditions religieuses du Proche Orient, faculté de théologie, Institut catholique de Lille) qui compte aussi plusieurs intervenants. Les conférences ont été filmées et seront prochainement diffusées sur internet. Les actes seront publiés dans la collection Acta Orientalia Belgica Subsidia.

3 C'est le personnage de Moïse, figure centrale du Pentateuque et de l'ensemble de la Bible, Ancien et Nouveau Testament, qui constitue le fil rouge des différentes interventions. Pourtant, en dehors du Pentateuque, on note que Moïse est relativement peu présent : seul $8 \%$ des 770 occurrences de Moïse dans la Bible hébraïque se trouvent hors du Pentateuque et du livre de Josué. Ainsi, il n'est mentionné que 5 fois chez les prophètes postérieurs et aucune fois dans la littérature de sagesse et dans les cinq rouleaux festifs de la section des Écrits. On le trouve 16 fois dans Josué, 8 fois dans les Psaumes et 31 fois dans les livres d'Esdras, Néhémie et les Chroniques, ainsi que deux fois en Daniel. Comment faut-il l'interpréter ces différences?

4 Dans la disposition chrétienne des livres bibliques qui place les prophètes écrivains en dernière position, l'Ancien Testament tout entier s'achève sur une évocation, quelque peu mystérieuse, de Moïse, en lien avec la Loi, aux côtés d’Élie : « ${ }^{22}$ Souvenez-vous de la 
Loi de Moïse, mon serviteur, à qui j'ai donné, à l'Horeb, des lois et des coutumes pour tout Israël. ${ }^{23}$ Voici que je vais vous envoyer Élie, le prophète, avant que ne vienne le jour du SEIGNEUR, jour grand et redoutable. ${ }^{24} \mathrm{Il}$ ramènera le cœur des pères vers leurs fils, celui des fils vers leurs pères pour que je ne vienne pas frapper la terre d'interdit » (Ml 3,22-24).

5 Le personnage de Moïse garde son rôle exemplaire à travers les siècles. Ainsi, au quatrième chapitre de la sixième demeure du "Château intérieur " (Euvres complètes (trad. Marcelle Auclair), Paris, Desclée de Brouwer, 1995, p. 970), Sainte Thérèse d'Avila se réfère à lui.

On pourrait évoquer longuement la réception du personnage de Moïse chez les Pères de l'Église, au Moyen Âge et à l'époque contemporaine, à commencer par sa reprise dans l'œuvre de Freud qui a marqué les débuts de la psychanalyse jusqu'aux blockbusters connus de beaucoup d'entre nous tels « Les dix commandements » ou, plus récemment, «Exodus ».

7 Cette journée n'avait pas la prétention de couvrir tout le champ de la réception de la figure de Moïse, qui est véritablement immense et mériterait assurément plusieurs jours. Les organisateurs se sont donc contentés d'aborder quelques aspects.

8 Ainsi, le personnage de Moïse ne vient pas de nulle part, mais s'est construit au fil du temps, au fil de l'histoire d'Israël et de l'élaboration des récits bibliques, en empruntant, peu ou prou, aux traditions des peuples alentours. À l'intérieur même du Pentateuque, on note que la figure de Moïse a un caractère polysémique qui est le résultat d'une pluralité de traditions. Ce fut le sujet de la première partie de la matinée, avec les exposés de Stéphanie Anthonioz et Christian Cannuyer.

La deuxième partie de la matinée fut consacrée à la réception de la figure de Moïse dans l'Ancien Testament en dehors du Pentateuque, et dans la littérature intertestamentaire, avec les exposés de Catherine Vialle et Didier Luciani.

Moïse s'avère aussi une figure fondamentale dans l'ensemble du Nouveau Testament, ce dont ont traité Michel Hubaut et, en ce centrant plus particulièrement sur Matthieu, Bruno Callebaut.

11 Fut ensuite évoquée la réception de la figure de Moïse dans les grandes traditions religieuses : le judaïsme, avec le Père Massonnet, le Coran et l'islam avec Samir Arbache et la tradition chrétienne, plus précisément sous l'angle de l'iconographie avec Dominique Guéry. 